\title{
O Desafio Diagnóstico do Novo Coronavírus: A Propósito de um Caso Clínico
}

\section{The Diagnostic Challenge of the New Coronavirus: A Case Report}

Vanda Jorge ${ }^{1}$, David Rodrigues², Maria Manuel Noronha ${ }^{3}$, Eduardo Pegado4

\section{RESUMO}

COVID-19 é o nome atribuído, pela Organização Mundial da Saúde, à doença provocada pelo novo coronavírus SARS-Cov-2, que pode causar infeção respiratória grave como a pneumonia, tendo sido declarada como pandemia a 11 de março de 2020. O conhecimento acerca dos seus testes diagnósticos ainda está em clara evolução, bem como a sua correta interpretação.

Apresentamos o caso clínico de um homem, de 67 anos, com história prévia de hipertensão arterial e glaucoma. Evidência de quadro clínico arrastado de febre, astenia e mialgias. Tomografia computorizada do tórax com infiltrados periféricos sugestivos de pneumonia atípica. Iniciou terapêutica protocolada com hidroxicloroquina e azitromicina, por elevada suspeição para COVID-19, apesar de só a terceira pesquisa de SARS-CoV-2 no exsudado faríngeo, ter sido positiva.

PALAVRAS-CHAVE: COVID-19; Exsudados e Transudatos; Infeções por Coronavírus/diagnóstico; Reação em Cadeia da Polimerase Via Transcriptase Reversa

1. Assistente Hospitalar de Medicina Interna do Hospital CUF Torres Vedras, Torres Vedras, Portugal. 2. Assistente de Medicina Geral e Familiar e Coordenador do Atendimento Permanente do Hospital CUF Torres Vedras, Torres Vedras, Portugal. 3. Assistente Hospitalar de Medicina Interna e Coordenadora do Internamento do Hospital CUF Torres Vedras, Torres Vedras, Portugal. 4. Assistente Hospital Graduado de Ortopedia e Diretor Clínico do Hospital CUF Torres Vedras, Torres Vedras, Portugal.

Recebido/Received: 30/05/2020 - Aceite/Accepted: 02/06/2020 - Publicado/Published: 30/06/2020

• Autor (es) (ou seu (s) empregador (es)) 2020. Reutilização permitida de acordo com CC BY-NC. Nenhuma reutilização comercial. ${ }^{\circledR}$ Author(s) (or their employer(s)) 2020. Re-use permitted under CC BY-NC. No commercial re-use. 


\section{ABSTRACT}

COVID-19 is the name attributed by the World Health Organization to the disease caused by the new coronavirus SARS-CoV-2, which can cause severe acute respiratory syndrome, such as pneumonia. It was declared a pandemic on 11 March 2020. The knowledge about the diagnostic tests is still evolving, as well as its correct interpretation.

We present a case of a 67-year-old male with history of hypertension and glaucoma. He had long lasting clinic of fever, asthenia and myalgia. Computed tomography scan of the chest showed peripheral infiltrates suggestive of atypical pneumonia. He started therapy with hydroxychloroquine and azithromycin, due to high suspicion for COVID-19 disease, despite the fact that only the third SARS-CoV-2 test in the pharyngeal exudate was positive.

KEYWORDS: Coronavirus Infections/diagnosis; COVID-19; Exudates and Transudates; Reverse Transcriptase Polymerase Chain Reaction

\section{INTRODUÇÃO}

Em dezembro de 2019, foi identificado na China, nomeadamente na província de Hubei, um surto pelo novo coronavírus SARS-CoV-2. Desde então, vários milhões de casos surgiram por todo o Mundo. A precocidade do diagnóstico, isolamento e tratamento destes doentes é essencial para reduzir a transmissão humana, nomeadamente entre os contactos próximos e os profissionais de saúde, prevenindo a sua disseminação explosiva. Seguindo as recomendações para o diagnóstico e tratamento da pneumonia causada pelo novo coronavírus SARS-CoV-2, e de acordo com a prática clínica adquiria na província de Hubei, a análise por RT-PCR (reverse transcriptase polymerase chain reaction) das secreções respiratórias foi a usada para detetar o vírus. Contudo, alguns investigadores e médicos argumentaram que a imagiologia pulmonar por tomografia computorizada, serviu para identificar vários casos com infiltrados pulmonares múltiplos, bilaterais, periféricos e em vidro despolido, em doentes com resultados por RT-PCR negativos. $^{1}$

Pelo Mundo inteiro verificou-se uma necessidade crescente em realizar testes diagnósticos para a COVID-19, com um encorajamento da Organização Mundial da Saúde em "testar, testar, testar".

A identificação do genoma completo do vírus, precocemente na epidemia, facilitou o desenvolvimento de testes para detetar o seu RNA. Múltiplos ensaios com diferentes alvos genéticos foram desenvolvidos, usando a RT-PCR. Estes testes utilizam normalmente amostras obtidas do trato respiratório, através de zaragatoas nasofaríngeas. A testagem para a COVID-19, permite, para além da identificação dos indivíduos infetados e rastreamento dos seus contactos próximos, apurar as taxas de infeção regionais e nacionais, de forma a orientar as intervenções da Saúde pública. Contudo, permanecem várias questões de como aplicar corretamente o resultado destes testes, de modo a tomar as decisões mais adequadas para os doentes e população. ${ }^{2}$

Com este caso clínico pretendemos chamar a atenção para a problemática do diagnóstico e orientação clínica desta nova identidade COVID-19, que de forma exponencial e extremamente rápida invadiu a nossa prática clínica diária.

\section{CASO CLÍNICO}

Doente do sexo masculino, 67 anos de idade, com história prévia de hipertensão arterial essencial e glaucoma, medicado em ambulatório com olmesartan/hidroclorotiazida e timolol/dorzolamida. Descreve quadro com dez dias de evolução caracterizado por febre, astenia e mialgias, tendo já efetuado ciclo de antibioterapia com azitromicina, por alegada pneumonia da comunidade. Recorreu ao Atendimento Permanente do Hospital CUF Torres Vedras, a 27/03/2020 por manutenção do quadro. Salientava-se, gasimetria bem ventilada e oxigenada, analiticamente com linfopénia de 1210/ $\mathrm{mm}^{3}$, PCR 8,3 mg/dL, LDH 404 U/L, AST 90 U/L e ALT 73 U/L. Pesquisa de SARS-CoV-2 inconclusivo no exsudado faríngeo. Radiologicamente infiltrados subpleurais bilaterais. Reavaliado a 29/03/2020, apresentando hipoxémia discreta de $74 \mathrm{mmHg}$. Análises sobreponíveis com d-dímeros de 759,61 ng/mL. Pesquisa de SARS-CoV-2 negativo no exsudado faríngeo. Tomografia computorizada do tórax com áreas de densificação em vidro despolido, com envolvimento bilateral e distribuição preferencialmente periférica, enquadráveis num contexto de processo inflamatório/pneumonia atípica (Fig.s 1 e 2). Dada a elevada suspeição de pneumonia por SARS-CoV-2, foi transferido para o Hospital CUF Infante Santo. Iniciou protocolo terapêutico com hidroxicloroquina (400 mg bid no primeiro dia e posteriormente 200 mg bid) durante 7 dias e azitromicina (500 mg no primeiro dia e posteriormente $250 \mathrm{mg} / \mathrm{dia}$ ) durante 5 dias. Repetiu pesquisa 
de SARS-CoV-2 no exsudado faríngeo, a 31/03/2020 que se revelou positivo. Evolução favorável, do ponto de vista clínico, com apirexia mantida, e analítico, tendo alta clínica ao sétimo dia de internamento.

\section{DISCUSSÃO}

O teste mais frequentemente usado e confiável para o diagnóstico da COVID-19 tem sido a RT-PCR, realizado após colheita do exsudado nasofaríngeo, orofaríngeo, ou mais recentemente de saliva. Na maioria dos doentes sintomáticos, o RNA viral nasofaríngeo é detetável desde o primeiro dia dos sintomas, mas o seu pico surge a partir da primeira semana. No entanto, uma PCR "positiva" reflete apenas a deteção do RNA viral e não indica necessariamente a presença de vírus viáveis, podendo o teste manter-se positivo mesmo após a sexta semana pós-diagnóstico. Foram ainda relatados casos positivos após 2 testes negativos consecutivos, realizados com 24 horas de intervalo. Não está claro se é um erro do teste, reinfeção ou reativação. Num estudo com 205 doentes com infeção confirmada, a positividade da RT-PCR foi maior em amostras de lavado broncoalveolar (93\%), seguidas de secreções brônquicas (72\%), esfregaço nasal (63\%) e esfregaço faríngeo (32\%). Os falsos negativos ocorreram principalmente devido à análise precoce em relação com o início da doença e também por incorreta colheita de amostra, principalmente nas zaragatoas nasofaríngeas. Os falsos positivos podem ocorrer, ocasionalmente, devido a erros técnicos, como a contaminação do reagente. ${ }^{3}$

Para além do tipo de amostra, a precisão do teste varia em função do estadio da doença, grau de replicação e de eliminação do vírus. ${ }^{2}$ É ainda mais sensível nos doentes com sintomatologia sugestiva de síndrome gripal, nomeadamente nos que apresentam febre. ${ }^{1}$

Recomenda-se que o diagnóstico microbiológico seja efetuado por PCR em tempo real nas amostras do trato respiratório superior (exsudado da nasofaringe e orofaringe, colhidos com zaragatoa), sempre que possível associada a amostra do trato respiratório inferior (secreções brônquicas colhidas por aspirado endotraqueal). ${ }^{4}$

Estimativas atuais, após várias revisões sistemáticas, apontam aproximadamente uma sensibilidade de 70\% e uma especificidade de 95\% para a RT-PCR. Neste contexto, um teste positivo tem maior peso do que um teste negativo, devido à sua alta especificidade. Um único teste negativo não deve ser usado como regra em doentes com sintomas sugestivos. ${ }^{2}$ Nos doentes com suspeita de COVID-19 e uma PCR inicial negativa, a repetição da RT-PCR revelou-se positiva em 23\% dos casos. Nestas situações, sempre que possível, deve ser efetuada uma tomografia torácica. ${ }^{4} \bigcirc$ padrão mais comum $(76,4 \%)$ na tomografia torácica é a presença de opacidades em vidro despolido e infiltrados bilaterais. ${ }^{5}$

A infeção por SARS-CoV-2 também pode ser detetada indiretamente, medindo a resposta imunológica do hospedeiro. O diagnóstico serológico é especialmente importante nos casos leves a moderados com apresentação tardia, para além das duas primeiras semanas do início da doença. Pode ainda ter relevância na compreensão da disseminação da COVID-19 numa comunidade. O marcador serológico mais sensível e mais precoce são os anticorpos totais, cujos níveis começam a aumentar a partir da segunda semana do início dos sintomas. Os testes aos anticorpos IgM e IgG por ELISA (enzyme-linked immunosorbent assay) têm mais de 95\% de especificidade para o diagnóstico da COVID-19. A utilização conjunta da RT-PCR inicialmente, com os testes serológicos
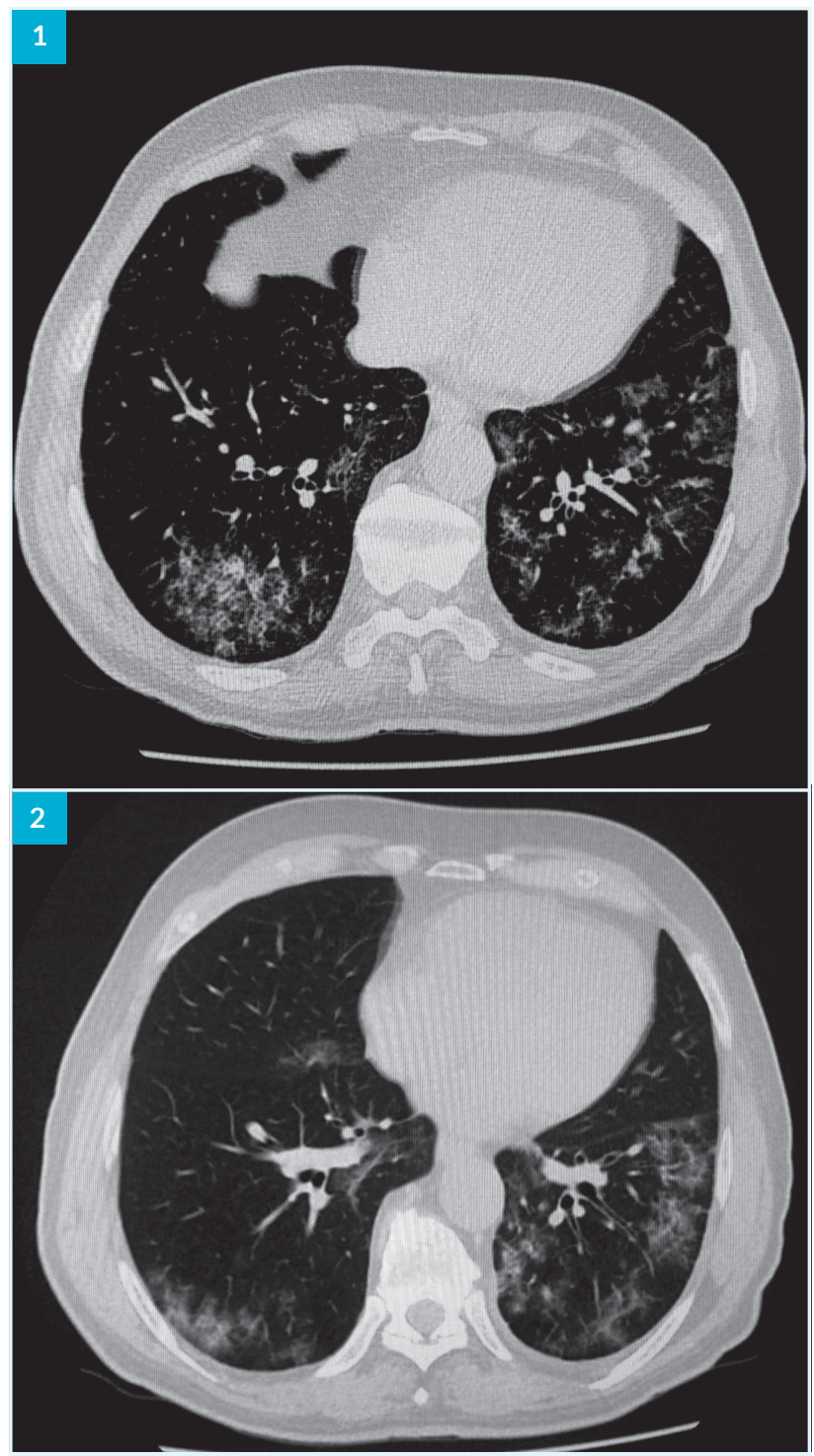

FIGURAS 1 e 2. Tomografia computorizada do tórax, mostrando áreas de densificação em vidro despolido com envolvimento bilateral e distribuição preferencialmente periférica. 
duas semanas depois, pode aumentar a precisão do diagnóstico. ${ }^{3}$ Apesar do enorme esforço para estudar as respostas imunológicas da COVID-19, até à data, ainda não há dados definitivos acerca da duração da presença dos anticorpos após infeções assintomáticas, leves e graves. Sublinha-se o perigo do uso destes testes para a avaliação do risco individual, mas destaca-se o seu potencial em termos epidemiológicos. ${ }^{6}$

Os testes rápidos utilizam um sistema qualitativo de deteção de IgG/lgM. Quando comparados com o teste RT-PCR (gold standard) apresentam baixa sensibilidade. Neste contexto, são pouco úteis enquanto método de rastreio da comunidade tendo em conta o elevado número de falsos negativos.?

\section{CONCLUSÃO}

Este caso pretende ilustrar a complexidade do diagnóstico da COVID-19. Uma nova entidade que mantém a comunidade científica cheia de dúvidas e com muito poucas certezas. Diariamente vão surgindo novos estudos que mostram isso mesmo.

E a problemática vai para a além do diagnóstico, passando pela terapêutica de suporte, que tem levado à suspensão progressiva da hidroxicloroquina em vários países por questões de segurança, até à duração de imunidade dos indivíduos assintomáticos e sintomáticos, infetados pelo SARS-CoV-2, entre muitas outras.

O caminho releva-se longo e tortuoso, mas decerto sairemos dele mais enriquecidos em termos pessoais e profissionais, podendo contribuir para a história da humanidade.

\section{RESPONSABILIDADES ÉTICAS}

CONFLITOS DE INTERESSE: Os autores declaram a inexistência de conflitos de interesse na realização do presente trabalho.

FONTES DE FINANCIAMENTO: Não existiram fontes externas de financiamento para a realização deste artigo.

CONFIDENCIALIDADE DOS DADOS: Os autores declaram ter seguido os protocolos da sua instituição acerca da publicação dos dados de doentes.

CONSENTIMENTO: Consentimento do doente para publicação obtido.

PROVENIÊNCIA E REVISÃO POR PARES: Não comissionado; revisão externa por pares.

\section{ETHICAL DISCLOSURES}

CONFLICTS OF INTEREST: The authors have no conflicts of interest to declare.

FINANCING SUPPORT: This work has not received any contribution, grant or scholarship.

CONFIDENTIALITY OF DATA: The authors declare that they have followed the protocols of their work center on the publication of data from patients.

PATIENT CONSENT: Consent for publication was obtained.

PROVENANCE AND PEER REVIEW: Not commissioned; externally peer reviewed.

\section{REFERÊNCIAS}

1. Liu R, Han H, Liu Fang, Lv Z, Wu K, Liu Y, et al. Positive rate of RT-PCR detection of SARS-CoV-2 infection in 4880 cases from one hospital in Wuhan, China, from Jan to Feb 2020. Clin Chim Acta. 2020; 172-5. doi: 10.1016/j.cca.2020,03.009.

2. Watson J, Whiting P, Brush J. Interpreting a covid-19 test result. BMJ. 2020 (in press). doi: 10.1136/bmj.m108.

3. Sethuraman N, Jeremiah S, Ryo A. Interpreting diagnostic tests for SARS-CoV2. JAMA. 2020 (in press). doi: 10.1001/ jama.2020.8259.

4. Mendes J, Mergulhão P, Froes F, Paiva J, Gouveia J. Recomendações da Sociedade Portuguesa de Cuidados Intensivos para a abordagem COVID-19 em Medicina Intensiva. Sociedade Portuguesa de Cuidados Intensivos. 2020 [acessed 2020 March 31]. Available: https://www.spci.pt/media/covid-9/COVID 19 R 20200331.pdf.

5. Wang $\mathrm{Y}$, Kang $\mathrm{H}$, Liu $\mathrm{X}$, Tong Z. Combination of RT-qPCR testing and clinical features for diagnosis of COVID-19 facilitates management of SARS-CoV-2 outbreak. J Med Virol. 2020:92:538-9. doi: 10.1002/jmv.25721.

6. Bryant J, Azman A, Ferrari M, Arnold B, Boni M, Boum Y, et al. Serology for SARS-CoV-2: Apprehensions, opportunities, and the path forward. Sci Immunol.2020 (in press). doi:10.1126/ sciimmunol.abc6347.

7. Dohla M, Boesecke C, Schulte B, Diegmann C, Sib E, Richter, et al. Rapid point-of-care testing for SARS-CoV-2 in a community screening setting shows low sensitivity. Public Health. 2020;182:170-2. doi:10.1016/j.puhe.2020.04.009 